The purpose of moving Plan B to Schedule II was to make it more accessible to women (thus reducing unwanted pregnancies and abortions), while still ensuring the appropriate level of counselling from a trained health professional. Pharmacists have no interest in a woman's sexual history except to determine if Plan B, which has maximum effectiveness for only 72 hours, is appropriate for their situation, as outlined in the assessment in SOGC's clinical practice guidelines on EC. ${ }^{3}$ The guidelines are not new and represent best standards of practice. A physician or nurse practitioner would ask a woman requesting EC the same questions. Many women who ask for Plan B have a lot of questions and misinformation, and appreciate the opportunity to speak with a pharmacist. Pharmacists frequently find that a fair number of women who ask for EC do not, in fact, require it and therefore do not pay for or use an unnecessary drug. When providing EC, pharmacists also routinely refer women to a physician for long-term birth control and screening for STDs. ${ }^{4}$

It is interesting that the article concludes by admitting that no women have complained to privacy commissioners. We believe that women are actually benefiting from pharmacist counselling on EC, and this is an issue manufactured by $C M A J$ to grab some headlines. The real health issue that $C M A J$ should be addressing is that in Canada $I$ in 4 pregnancies ends in abortion. Increased access to emergency contraception with an opportunity for the woman to consult with a health professional can significantly reduce the number of unwanted pregnancies.

\section{George Murray}

President, Canadian Pharmacists Association

\section{REFERENCES}

I. Eggertson L, Sibbald B. Privacy issues raised over Plan B: women asked for names, addresses, sexual history. CMAJ 2005;173(I2):1435-6.

2. Emergency contraception moves behind the counter [editorial]. CMAJ 2005;172(7):845.

3. Society of Obstetricians and Gynaecologists of Canada. SOGC Clinical Practice Guidelines. 2003. Available: www.sogc.org/guidelines/pdf/psızı.pdf (accessed 2005 Dec I2).
4. Soon JA, Levine M, Osmond BL, et al. Effects of making emergency contraception available without a physician's prescription: a population-based study. $C M A J$ 2005;172(7):878-83.

Competing interests: None declared.

DOI:I0.1503/cmaj.051612

\section{[CMAJ responds:]}

We agree that Plan B's nonprescription status is a step in the right direction. ${ }^{1}$ We have no interest in waging a "campaign" against pharmacists, only in examining the potential impact of mandatory counselling on individual women. Our news article on emergency levonorgestrel (Plan $\mathrm{B})^{2}$ presents divergent points of view on behind-thecounter access, including that of the CPhA. Women we spoke to reported varying degrees of comfort with the dispensing process.

If controversy results from reporting on actual policies, so be it. The absence of direct complaints does not settle the matter; one may reasonably speculate that it indicates a general level of comfort with the dispensing procedure, but it may also reflect a lack of awareness of privacy guidelines and complaints procedures, or a reluctance to bring further attention to a transitory personal circumstance. Whatever the case may be, more than one provincial commissioner has thanked the journal for bringing this issue to their attention, and the Ontario College of Pharmacists has already agreed to revise their guidelines. ${ }^{3}$ The question of the security of data in a convenience store or supermarket is moot, as off-the-shelf availability implies that no personal information would be requested in the first place.

\section{Anne Marie Todkill \\ Senior Deputy Editor \\ CMAJ}

\section{REFERENCES}

I. Emergency contraception moves behind the counter [editorial]. CMAJ; 2005;172(7):845.

2. Eggertson L, Sibbald B. Privacy issues raised over Plan B: women asked for names, addresses, sexual history. CMAJ 2005;173(I2):I435-6.

3. Information and Privacy Commissioner/Ontario. Controversial morning-after pill screening form scrapped in Ontario [news release]. 2005 Dec 7.

DOI:IO.I503/cmaj.I050264

\section{Biopeptides and immune exclusion}

Successful probiotics have the ability to adhere to the gut preventing attachment of pathogenic bacteria and help to restore immunologic quiescence. Unfortunately, Nandini Dendukuri and colleagues' systematic review ${ }^{1}$ was unable to find clinical benefit for treatment of Clostridium difficile-associated diarrhea (CDAD).

The important question is, Can probiotics or biologically active peptides induce a lasting immune response? Probiotics stimulate the synthesis and secretion of polymeric IgA, the antibody that protects mucosal surfaces against harmful bacterial invasion, the concept underlying immune exclusion. Appropriate colonization with probiotics can thus help to produce a balanced $\mathrm{T}$ helper (Th) cell response. An imbalance in Th cells partly contributes to clinical disease: Th2 imbalance contributes to atopic disease and Thr imbalance contributes to Crohn's disease and Helicobacter pylori-induced gastritis.

LeBlanc and colleagues ${ }^{2}$ demonstrated that oral administration of an immunologically active peptide (derived after extensive proteolysis by Lactobacillus helveticus) enhanced immunomodulatory action and increased IgA+ Blymphocytes in the intestinal lamina propria of mice, and offered protection against further Escherichia coli $0157: \mathrm{H}_{7}$ challenge. Benyacoub and colleagues ${ }^{3}$ showed that the probiotic organism Enterococcus faecium SF68 offered specific humoral and cellular (increased $\mathrm{CD}_{4}+$ in Peyer's patches and spleen) responses against Giardia intestinalis infection in mice.

Perhaps we are just beginning to understand the complex coexistence and interdependence between microbes and man.

\section{Sujoy Khan}

Department of Immunopathology

St. Bartholomew's Hospital

West Smithfield, London, UK

\section{REFERENCES}

I. Dendukuri N, Costa V, McGregor M, et al. Probiotic therapy for the prevention and treatment of 